\title{
DAS RELAÇÕES ENTRE A MODERNIDADE E O FUNDAMENTALISMO RELIGIOSO
}

\author{
The relationships between modernity \\ and religious fundamentalism
}

\author{
Otávio Barduzzi Rodrigues da Costa*
}

\section{RESUMO}

Neste artigo pretende-se apontar certas relações em uma das consequências da modernidade no que se refere à religião: o fundamentalismo. Tem-se como objetivo mostrar aqui que o último é resultado direto do primeiro, e que tomou certas proporções após os acontecimentos de setembro de 2001, e que a ciência das religiões não deve ficar silente. Procurará descrever, sem esgotar o assunto, o que é modernidade, apontar suas crises, e mostrar esse aspecto religioso do qual tem uma relação causal.

Palavras-chave: Modernidade. Fundamentalismo. Religião.

\section{ABSTRACT}

This paperwork intends show up some relations about the modernism consequence in the religious aspect, the fundamentalism. Pretends show here that the last is a direct result of the prime and his crisis, and that increase up after the relates occurred in September of 2001, the Science of religion don't must have stay in silence about. Find describe, without end the theme, what is modernity, show up your crises and show this religious aspect that's have some causal relationship.

Keywords: Fundamentalism. Modernit. Religion.

* O autor é antropólogo e mestre em filosofia pela UNESP, doutorando em ciências da religião pela UMESP; é professor assistente do Departamento de Ciências Humanas da Universidade Metodista e do IFSP.<otavio.costa@metodista.br>.

\begin{tabular}{|l|l|l|l|l|l|}
\hline Teocomunicação & Porto Alegre & v. 44 & n. 2 & p. 220-246 & maio-ago. 2014 \\
\hline
\end{tabular}




\section{Introdução}

Há certas relações entre a modernidade e o fundamentalismo religioso. Em primeiro lugar, não é fácil definir o que é modernidade, mesmo porque se vive nesse momento histórico. Fica muito mais fácil analisar a antiguidade porque vive-se fora dela, o mesmo para a idade média, mas é muito difícil analisar o momento histórico no qual se vive. Kant (1996) afirma, ao criticar o historicismo racional, que não podemos conhecer inteiramente a época em que vivemos. Mas, como analisar algo em cujo momento-espaço se está inserido? É mais difícil ver os movimentos quando se está jogando xadrez do que quando se está como observador externo.

Longe de ser uma figura de linguagem barata, a comparação anterior ao jogo de xadrez remete a uma velha discussão da ciência: o distanciamento científico. Para Bourdieu (1974), a ciência e o conhecimento moderno foram baseados em duas formas de conceber a realidade das coisas originadas no mesmo contexto histórico, a França do século XVIII, cujas bases são o Racionalismo e o Positivismo. Tais bases implicam várias consequências epistemológicas, sendo uma delas o distanciamento cientifico. Esta metodologia de descrição e análise da experiência implica um ideal positivista da neutralidade e do distanciamento "científico" do observador relativamente ao objeto para investigar a verdade "pura".

Tal paradigma, porém, é uma suposição falha. Há uma suposta neutralidade do discurso científico e sobre a suposta necessidade de distanciamento do pesquisador em relação ao seu objeto de pesquisa. Todo discurso (as pesquisas, descobertas científicas se traduzem em discursos também) é produzido por uma pessoa, que é o sujeito desse discurso, e traz as marcas desse sujeito, que vive num determinado tempo e espaço.

Os ideais humanos são frutos das ideias e valores vigentes na época e no espaço em que vivemos (MORIN, 2000). O trabalho científicotecnológico é trabalho humano, e traz as marcas de seus valores e opiniões (MORIN, 1999). Não há neutralidade, toda humanidade está imersa na sua história (MORIN,1996). E não é possível um "distanciamento" entre o pesquisador e o objeto da pesquisa: na verdade, sempre se está envolvido com nossas investigações. A ideia de distanciamento científico, na verdade, vem da época do Iluminismo. É, portanto, uma criação humana como qualquer outra. 
O próprio projeto e conhecimento racionalista era uma opinião de pessoas (cientistas), que simplesmente acharam que assim se estaria no caminho de uma verdade pura. O projeto de conhecimento do positivismo era propor a ciência como único aspecto verdadeiro de dizer o que é ou não verdade (MORIN, 1983). Isso é chamado de dimensão ética da ciência construída e europeizada.

\section{A modernidade na história, na razão e na religião}

Não é fácil localizar a modernidade na história (HUYSSEN, 1986). Vários autores divergem, alguns dizem que começou com a invenção dos estados- nação, outros com a queda da Bastilha, outros dizem que foi com a invenção da máquina a vapor de James Watt, mas a maioria das escolas históricas está de acordo que começou com as grandes navegações e a queda de Constantinopla (REIS, 2006). Modernidade é a denominação de um conjunto de fenômenos sociais e é também o resultado de uma série de eventos marcantes no mundo ocidental ocorridos nos últimos quinhentos anos, aproximadamente.

Mais do que uma focalização e um ponto fixo na história, a modernidade é uma condição humana, é uma crença na certeza do cientificismo e da racionalidade, na qual as relações sociais são mudadas. Seu termo seguido - pós-modernidade - não é algo dividido dela, é apenas a maximização do individualismo, enquanto na modernidade o seu ápice ideológico, a focalização dos supostos direitos foram direitos políticos. Hoje o foco é o indivíduo, mas considero isso apenas uma consequência da modernidade e não um período disjuntivo dela. Talvez a melhor definição de pós-moderno seja a de Lyotard. O pósmoderno, como Lyotard (1984) o definiu, é «a incredulidade para com as metanarrativas", inclusive é uma crítica às representações religiosas. E uma maximização do projeto moderno de independência de Deus (idem) ao homem que fica individualizado na história e, portanto, egoísta.

A modernidade trouxe uma nova consciência do sentido histórico, uma nova representação da temporalidade histórica e, com ela, o mundo se fragmentou em valores distintos. O espírito capitalista é moderno, desencantado, secularizado, racional. A modernidade é o desenvolvimento do processo de progresso, revolução, utopia; a ideia de história está dominada pelos conceitos de razão, consciência, sujeito, verdade e universalidade. 
Como bem assinala o bioquímico francês Jaques Monod (1971), tanto na ação quanto no discurso, o conhecimento racional está "necessariamente" associado a uma escala de valores, escala essa que vai determinar, em última análise, a definição do que é propriamente "verdadeiro" no campo do conhecimento. Mas, como também ressalta Monod, a ciência fundada no postulado da verdade objetiva trata verdade e valor como elementos antagônicos, próprios de domínios que se excluem. Nesse sentido é que se pode dizer que, quanto mais próximo está o pesquisador do chamado "núcleo duro" da ciência, mais estará lidando com a chamada "pesquisa pura", e mais tenderá "a relegar a um segundo plano qualquer discussão a respeito das consequências éticas de suas elucubrações teóricas ou mesmo negar sumariamente (idem) que elas existam". Assim as éticas, práticas e crenças religiosas são deixadas de lado.

Desde o advento e aceitação geral do Positivismo lógico, cujo objetivo era tornar toda forma de conhecimento científico, ou melhor, a busca por uma nova verdade pura, surgiu um ideário de que o cientista não deveria se envolver com seu objeto de pesquisa, ou seja, deveria estar distante do seu objeto de pesquisa para se poder analisá-lo com neutralidade. Como afirma Gonçalves (2007), não é possível contrapormos atividade científica aos elementos subjetivos, afeto e emoção, como os positivistas acreditavam.

Vítor Westhele (1992), faz a seguinte pergunta: Por que a teologia (omissis...) deveria se interessar pela discussão sobre a crise na modernidade? Várias são as repostas, mas a ideia principal do texto é que toda forma de conhecimento que não foi ciência produzida e inventada em um jogo de poder que interessa ao capitalismo norte-americano e europeu não é tido como verdade.

Houve um sequestro de saberes no sentido que Focault (2008) descreve, ou seja, todos os saberes ou conhecimentos que não são ciências, dentre os quais se inclui o conhecimento religioso, foram brutalmente esquecidos e tidos pelo grande sistema de que se constitui a ciência, como mitologia e não verdade. Foucault propõe ressurreição dos saberes subjugados. Esses saberes subjugados são, por um lado, conteúdos históricos eruditos e rigorosos que foram mascarados sob sistematizações formais e que permitem desvendar as lutas que essas sistematizações pretendem dissimular, e, por outro lado, saberes das pessoas, particulares, regionais, desqualificados. A teologia e o conhecimento religioso foram relegados a uma inverdade pelo projeto de conhecimento da modernidade. 
A Modernidade, a princípio, é o período histórico que se estende entre fins do século XV e os dias atuais. Contudo, além de um período histórico, a Modernidade é a denominação de um conjunto de fenômenos sociais e é também o resultado de uma série de eventos marcantes no mundo ocidental ocorridos nos últimos quinhentos anos. "Mundo Ocidental" seria, neste ponto, a Europa Ocidental: GrãBretanha, França, "Alemanha", "Itália", Áustria, Suíça, Países Baixos, Portugal e Espanha. Os países com nomes entre aspas não formavam uma única nação na época. No pós-primeira guerra os EUA e Japão (já extremamente imersos no capitalismo cientificado e ocidental) se tornam parte importante do "Mundo Ocidental"

Circunscrita no tempo, a modernidade pode ser associada a um período histórico e como tal, difícil de ser analisado, pois é, ao mesmo tempo, passado e presente. Mesmo considerando a dificuldade de se distanciar do que se tem para analisar, reflexivamente, os rumos do hoje e do porvir, esse movimento é extremamente importante para que possamos compreender os fenômenos sociais do nosso tempo (HUYSSEN, 1986).

Tecnológica e cientificamente, a modernidade fez o homem tornar-se providência para si mesmo, e hoje, para acabar com a fome, as doenças, as inundações, as epidemias, não recorre a Deus, como faziam seus antepassados, mas sim à medicina, à engenharia, à indústria, etc. (MONDIN, 1980). Modernidade, ao mesmo tempo em que é um período histórico indefinido, é uma crença na certeza do cientificismo e da racionalidade, na qual as relações sociais são mudadas.

Ter relações pautadas pela racionalidade (hegemônica no ocidente) não era uma oferta tão ruim frente a uma ideia da idade média, de um absolutismo rigoroso e de uma crueldade cristã que invadia e destruía reinos considerados bárbaros nas cruzadas ou queimava mulheres por pensarem diferentes acusando-as de bruxas (PEDRERO-SÁNCHES, 2000). Porém o projeto da modernidade se mostrou tão mais cruel do que a idade média. Temos liberdade, porém temos outros problemas tais como: exclusão, desigualdade, fome, dentre outros (MONDIN, 1980). É desta situação vivida que surgem novos problemas para as ciências humanas, com excesso de informação e de abundância em matérias que, no entanto não trouxeram a plena felicidade e organização social, com a desvalorização da força de trabalho, o excesso de produtividade e miséria, com o terror da exclusão social e dos impactos ambientais; situações que geram insegurança e desconforto. Mas, focando-se em um 
só aspecto da modernidade, existe a crença inevitável de que a ciência é a única verdade.

\section{A visão hegemônica do mundo}

A visão de mundo no moderno e em sua crise - o pós-moderno ${ }^{1}-$ foi a certeza de que o mundo devia ser visto através de uma lente racionalizada e cientificista, na qual Deus ou a teologia não teriam lugar. Ocorre que essa visão falhou fragorosamente em termos sentimentais porém teve o sucesso em conquistar o mundo. Em primeiro lugar, falhou em sua própria certeza: as ideias popperianas, a crise de paradigma de Khun, o fim das certezas de Prigogyne, bem como de outros cientistas como Feyerabend, Richard Rorty, Maturana e Morin (MORIN, PRIGOGINE, 1996), demonstraram que o racionalismo poderia ser questionado e que haveria novas possibilidades de um nova consciência ser descoberta. Inclusive Kuhn (1998) sugere ser impossível a existência de apenas uma única teoria administrativa capaz de fazer previsões e livres de valores.

O mundo na modernidade só pode ser válido por aquilo que poderia ser dado em um gráfico matemático, através do que Morin (1990) chama de paradigma Newtoniano-Baconiano-Cartesiano ou grande paradigma do ocidente. Surgiu uma forma hegemônica de conhecimento do que é válido, e conhecimento se torna poder econômico, e economia se torna números e gráficos. Assim, nesse mundo moderno, coisas abstratas são consideradas menos importantes como Deus, amor, arte etc. Além disso, algo que o mundo moderno proporcionou são as múltiplas "leituras da vida" através de fórmulas matemáticas e físicas. As coisas se tornam uniformes, com figuras, diagramas, lista e textos, e o cientista é aquele que é visto como a pessoa que mantém a humanidade como algo além dela mesma (RORTY, 1982), ou seja, exerce um sacerdócio também Assim as verdades que a humanidade busca foram imposta para serem respondidas pela ciência.

Assim Deus, e religiões não teriam lugar num mundo assim que para apropria a racionalidade, e suas produções, ciência e tecnologia fazem o que antes o homem recorria às suas divindades. Se hoje o homem quer chuva em uma plantação, não mais sacrifica uma virgem

Esse termo, pós - modernidade, segundo Touraine (1993, p. 37) significa apenas crise da modernidade. 
ao seu deus, mas recorre à engenharia hidrográfica. Se quer saber se vai chover, não mais consulta um oráculo e sim um moderno satélite. Há uma impressão constante, no mundo moderno, de que a frase de Nietzsche estava correta. "Deus está morto". Não há mais lugar para a metafísica. Segundo ele (1979), analisando certos mitos, afirma que não há um Deus e um Satanás como fonte de bem e de mal. O homem é que é bom ou mau, assim os valores absolutos bem e mal são tirados do plano dos deuses e entregue, ao homem.

A doutora em filosofia Luciene Félix (2008) proclama um apóstrofo comum na ciência, a qual Deus é contestado: Vem Galileu e diz que a terra (e o homem) não é o centro do universo; vem Marx e diz que religião é um ópio do povo; vem Nietzsche e diz que Deus morreu; vem Darwin e diz que descendemos dos animais; vem Freud e diz que não somos anjos travestidos. Assim o divino, em nós, é lentamente substituído pela ciência. Citando Luciene:

O evolucionista Charles Darwin (1809-1882), em sua famosa obra 'A origem das espécies', discorre sobre a teoria da evolução dos seres vivos mediante a seleção natural. Darwin prova por $a+b$ que descendemos dos primatas. Convém salientar que esse eminente britânico, embora afirmasse que religião nada mais é que 'estratégia tribal de sobrevivência', acreditava que Deus era o legislador supremo. O filólogo e filósofo alemão Friedrich Nietzsche (18441900), bebendo nas fontes gregas em 'O nascimento da tragédia', no culto ao orgiástico e desmedido dionisíaco, em contraponto à ordem e harmonia apolínea, identificou tensões de forças ocultas expressas na tragédia grega, especialmente nas dos pioneiros, Sófocles e Ésquilo. Considera Homero, insuperável. Também estudou o antiqüíssimo Zoroastrismo, religião que professa que seu 'deus' Ahura-mazda abarca o bem e o mal em si mesmo. Ou seja, que não há um Deus e um Satanás como fonte de bem e de mal, o homem é que é bom ou mau. Já o médico austríaco Sigmund Freud (1856-1939), considerado o 'Pai' da psicanálise, disciplina que intenta mapear 'geneticamente' a psique humana, revelou-nos o inconsciente e suas motivações. Também recorreu aos mitos e tragediógrafos gregos e, eis outro misterioso enlace matrimonial: as pulsões de Eros e Tânatos (pulsões de libido e de morte), ação e repouso, vida e destruição, sempre em conjunto. Freud afirma que o sentimento religioso de um vínculo indissolúvel, de algo ilimitado, sem fronteiras, essa sensação de eternidade, algo oceânico, por assim dizer, não passa de uma ilusão. Para ele, todo nosso histórico 
biológico, encontra-se preservado em nossa vida mental, psíquica. Tal sentimento pode ser identificado acompanhando o feto no interior do útero, onde se encontra no verdadeiro paraíso, com todas as necessidades satisfeitas, em prazer imperturbável e absoluto. Dessa 'memória' biológica (registrada em nosso inconsciente) deriva nossa sensação de plenitude, para onde sempre desejaremos regressar: (omissis) E acrescenta: 'É desnecessário dizer que todo aquele que partilha um delírio jamais o reconhece como tal'. Isso vai causar $O$ Mal-Estar na Civilização.

A modernidade e sua única fonte de verdade, a ciência, está limitada a vários fatores, porém foi extremamente influente no projeto moderno (RORTY, 1989). Porém "A ciência visa ao controle dos objetos e das coisas e não busca o puro conhecimento, pois sua finalidade está embotada pelo poder. Assim ela tira algumas coisas do campo de visão (idem)". A ciência diz o que é ou não é verdade, ${ }^{2}$ o que é ou não legítimo discutir. Westhelle (1992) pergunta: por que não discutir alquimia, astrologia, benzedura ou mesmo a existência de Deus?

Westhelle (1992), citando Latour, faz a pergunta deste: Que sociedade é esta onde uma formula matemática (que supostamente explica o universo ) tem mais credibilidade do que qualquer outra coisa: o senso comum, outros sentidos além da visão, uma autoridade política ou mesmo as escrituras? (parênteses nossos). Essa fórmula matemáticofísico-química teria poder de supostamente explicar o universo, mas não tem. Falhou em várias explicações, em dar sentido à vida, em explicar as sensações e memórias intimas que um cheiro pode trazer, em explicar o amor que falhou, no sentido moriniano, em explicar seu próprio projeto, visto que a ciência enfrenta agora uma crise em si mesma.

Para entender as ideias de Alain Touraine é imprescindível compreender o que entende ser modernidade. Conforme esse intelectual(2002), modernidade não se define apenas negativamente. Ela não se reduz ao que a expressão modernidade racionalista indica. Tal categoria de compreensão encerra nela a ideia da rejeição a tudo o que possa ser compreendido como não racional. Portanto ideias não racionalizadas, tal como a existência de Deus, não cabem mais na modernidade (Westhelle, 2008).

2 O fundamentalista não aceitará tal visão científica, Marty (1992) em contundente critica ao fundamentalismo, vai afirmar que o fundamentalista vê as explicações científicas como, em especial a evolução, como repugnantes, e patentemente falsas sobre a origem do universo e sobre a condição humana. 


\section{O triunfo da técnica}

A Modernidade, com sua razão instrumental, acabou substituindo a ideia de Deus pela Ciência. O que parecia apenas um pragmatismo acabou transformando-se em uma nova metafísica. Hoje se tem a impressão de que essa seja capaz de resolver todos os problemas e acredita-se que é uma crença infalível.

Houve um triunfo da técnica sobre o imaginário de divindade (BUBER, 2001). O triunfo da técnica tornou o homem o soberano da natureza, capaz de dominar as forças impetuosas e desfrutá-las para as próprias exigências. Com o triunfo da técnica, o homem tornouse providência para si mesmo, e pra isso, para acabar com a fome, as doenças, as inundações, as epidemias, agora não recorre a Deus, como faziam seus antepassados, mas à medicina, à engenharia, à indústria, etc.

Depois dos primeiros fáceis e compreensíveis entusiasmos com os enormes êxitos conseguidos, não somente entre as e mentes mais agudas e aperfeiçoadas (filósofos), mas em todos os ambientes, especialmente nos da juventude, estão se levantando, agora, críticas severas a respeito tanto da ciência como da técnica: acusam-nas de ter causado a perda dos valores fundamentais do espírito (SCHELER, 2003), de ter desumanizado o homem (BERNANOS, 1962), privando o indivíduo da liberdade (BUBER, 2001), do espírito de sociedade e da amizade, (HEIDEGGER, 2007), de ter provocado uma irreparável devastação do mundo, provocando a crise energética, o problema ecológico, etc. (CAPRA, 1982).

Scheler (2003) foi um dos principais autores a lançar uma denúncia vigorosa contra o ídolo da técnica: ela levou a uma subversão total dos valores; os valores de espírito não contam mais nada; a única preocupação que conta diz respeito apenas ao bem-estar, aos divertimentos, aos prazeres. Incapaz de viver os autênticos valores do espírito, o homem, que se deixou seduzir pelo ídolo da técnica, por fenômeno de ressentimento, os despreza e procura a afirmação de si mesmo na vontade de dominação do mundo, não mais visto como um meio para a realização dos valores mais altos, mas como fim em si mesmo, advindo, assim, a civilização da técnica, o industrialismo e o capitalismo. Ferreti afirma, analisando as obras de Scheler, o seguinte: 
Logo não há mais plenitude de vida, não mais o amor para o mundo e para a plenitude de suas qualidades, não mais a autocontemplação desinteressa como objetivo real do homem, mas cálculo utilitarista com fim em si mesmo, redução da natureza ao seu aspecto exatamente mensurável e seguramente dominável, fanatismo do trabalho e do lucro, avaliação somente das qualidades humanas de diligência, rapidez, capacidade de adaptação, que possuem uma utilidade aos fins lucrativos. O nascimento da ciência moderna e a concepção mecanicista da natureza não são as causas, mas sim os efeitos dessa nova atitude, que consagrou a natureza, privando-a de Deus, da alma, de todo valor e qualidade (FERRETI G.1982).

Além da perda dos valores do espírito, a ciência e a técnica causaram um desgaste profundo nas relações humanas. Buber (op. cit.) observou agudamente que, com o passar dos séculos, o mundo material se engrandeceu mais e mais, enquanto o mundo das relações pessoais pouco a pouco se restringiu. Um processo é a consequência do outro, visto que "o desenvolvimento da capacidade de experimentar e de utilizar cresce com a diminuição da capacidade do homem de criar uma relação dialógica" (BUBER, 2001, p. 65). Hoje, parece que a relação dialógica ficou menor, e que tenha cedido lugar àquela do domínio entre homens e de subjugação entre estes e a natureza.

A habilidade e a facilidade com que o homem cria técnicas sempre novas e mais perfeitas provocou, nas gerações recentes, uma confiança sem limites no progresso humano, nas possibilidades de levá-lo à frente até a realização do paraíso na terra e à feliz solução de todos os problemas e mistérios do homem. Mas é realmente verdade que as ciências e a técnica têm o poder de resolver todos os problemas e enigmas humanos? Não tem, o fundamentalista percebe isso e reage contra isso.

Aliado a toda manutenção de conhecimento único, surge a ideia de que conhecimento é poder (WESTHELLE, 1992) e que esse poder foi jungido ao capital e a serviço desse, ou seja, a ciência foi submetida ao interesse do capital (PANIKKAR, 2005). Sendo assim o poder ao qual se refere Marcuse (1967) em sua crítica à modernidade é o próprio capital. Para entender o trunfo do capital sobre os valores antes religiosos, houve um triunfo da comunicação que trouxe e confirmou a modernidade e propôs sua própria crise (BOLAÑO, 1998). A pós-modernidade ${ }^{3}$ é

3 Termo problemático, designa crise da modernidade. Não vivemos em uma pósmodernidade. É apenas um termo que vai designar que ela está em crise, não consenso entre os autores do que exatamente significa esse termo. 
apenas o ápice da modernidade, de onde se verifica que a ciência e a tecnologia foram usadas pelo capitalismo.

Surgiram, no seio da modernidade, novas tecnologias da comunicação, produtos dessa ciência racionalizada, que levou o homem a um movimento de consumo desmedido e capitalizado. As pessoas passaram a ser valoradas não pela sua essência, e sim pela sua capacidade de consumo. Termos antes caros à humanidade e à teologia como alma, bondade, caridade não tiveram mais lugar.

Horkheimer (1951), na obra sobre conceito de razão, baseada em conferência homônima, afirma que o positivismo caracterizase por conceber um tipo de razão subjetiva, formal e instrumental, cujo único critério de verdade é seu valor operativo, ou seja, seu papel na dominação do homem e da natureza. Esse mesmo autor, nessa obra, confirma que o positivismo é produto da modernidade.

A modernidade a tudo racionaliza, a tudo matematiza, a tudo contabiliza, a tudo registra de tal maneira que o homem fica reduzido a um negócio de contabilidade, que interessa particularmente aos registros das taxas e dos seguros (Steuerug und Sicherrung), para utilizar uma expressão de Heidegger (2007). Vale dizer que não só o homem, mas a própria natureza ficou submetida a sua valoração econômica (DONNELLY, 1999).

Mais do que o racionalismo, a modernidade reduziu o homem a um conceito numérico financeiro. A sua nova fé seria o dinheiro. Leonardo Boff $(1992)^{4}$ diz que há uma nova religião da mercadoria, uma crença que move toda a sociedade moderna (pós?): o dinheiro. E esse "dinheiro move céus e terra".

\section{A comunicação moderna}

A comunicação e a propaganda, que surgiram no advento da modernidade, foi a sua configuração máxima de deixar os valores humanos de lado, surgindo como um novo valor. A modernidade cria indústrias e uma delas é a cultural que supõe-se estar a serviço do projeto moderno. O desejo mercadológico cultivado pelos meios de comunicação passa a ser a nova religião, passa a ser objeto de adoração

\footnotetext{
4 Embora a autoria do presente artigo não concorde com todas as ideias do teólogo, respeita suas credenciais como intelectual.
} 
e de alcance dos povos em uma maximização (BOFF, 1992) do fetiche da mercadoria (MARX, 1996).

Abordando a questão da indústria cultural ou da cultura de massa, tratada por Theodor Adorno (1971), este diz que a indústria cultural fabrica produtos adaptados ao consumo das massas ao mesmo tempo em que determina esse consumo. O consumidor, para Adorno (idem), torna-se objeto da indústria, que especula sobre o comportamento das pessoas e o determina. Nesse contexto, a arte e a cultura, produzidas no estilo da indústria cultural, transformam-se em mercadorias, são produzidas em série e tornam-se banalizadas, sempre visando ao lucro. ${ }^{5}$ Nesse contexto, a religião só importa se estiver envolvida com o lucro, a oferta de encontro divino, ou salvação da alma, nesse contexto não serve para nada.

Adorno (1971) critica a ideologia da indústria cultural que quer fornecer aos homens o que devem ser e como se orientar. Para ele, tal indústria precisa fundamentar-se em si mesma e no confronto com os homens, que é exatamente o que a indústria cultural rejeita. Esse confronto surge porque o consumidor se torna um mero objeto, sem vontade própria, dominado pela indústria cultural. O objetivo último da indústria cultural, segundo este autor (ADORNO, 1971) é a dependência e a servidão dos homens. Ela tolhe a consciência das massas e, segundo ele, impede a formação de indivíduos autônomos, independentes, capazes de julgar e de decidir conscientemente.

Uma das características fundamentais da modernidade, segundo as críticas de Alain Touraine (2002), é a de que ela se torna produção e consumo de massa, em que o mundo "puro da razão" é invadido pelas multidões que colocam os instrumentos da modernidade ${ }^{6}$ a serviço do desejo e da mercadoria. No campo cultural, um bom exemplo é a televisão que massifica os gostos do indivíduo (BAUDRILLARD, 1979). Já o industrialismo trouxe a dominação social por meio do taylorismo, nazismo e stalinismo, que transformaram a sociedade em uma grande fábrica disciplinada e acrítica (idem).

Inclusive há uma crise da ética. A ética e a crise da modernidade têm sido um dos temas mais discutidos na atualidade (MARTELLI, 1995). É uma discussão que surge quando nem ao menos se tem uma definição geral de modernidade. O que é a modernidade? Não se

\footnotetext{
5 Há diversas que estão.

6 No caso, a tecnologia, sobretudo a de comunicação.
} 
sabe. Ela é a fusão do múltiplo, do heterogêneo, do fragmentado, do efêmero, onde se envolve atividade racional, científica, tecnológica e administrativa (idem). Basicamente, existem duas figuras condensadoras da modernidade: a racionalização e o positivismo (GIDDENS, 2000). Assim, valores humanos e suas expressões como o religiosos, o sagrado são deixados de lado. Valores como honra são substituídos por compromisso em pagar; valores como propriedade privada são mais defendidos que a vida, dentre outros exemplos.

Nas condições da modernidade, o que é místico, religioso, sagrado, não só é desprezado como outras coisas vão tomando seu lugar, segundo Giddens (1991). O ritual é reinventado e reformulado. O mesmo ocorre com o guardião, substituído pelo especialista, pelo perito. A modernidade reincorpora a tradição, reinventa-a, e, nesse sentido, também expressa continuidade. Grande parte dos valores relacionados à tradição permanecem e se reproduzem no âmbito da comunidade local. Na verdade, as primeiras instituições da modernidade não podiam desconsiderar a tradição preexistente e, vários aspectos dependiam delas, uma vez que foram/são ${ }^{7}$ usadas para domínio e superação dessas mesmas tradições.

Porém, segundo Ozaí Silva (2005) declara, a modernidade teve que "inventar" tradições e romper com a "tradição genuína", isto é, aqueles valores radicalmente vinculados ao passado pré-moderno. A modernidade, nesse sentido, expressa descontinuidade, a ruptura entre o que se apresenta como o "novo" e o que persiste como herança do "velho". A modernidade expressa:

a) ruptura com a ideia de comunidade (una e corporificada no dirigente) e passagem à ideia de sociedade (dividida em interesses conflitantes, classes antagônicas e grupos diversificados);

b) ruptura com a ideia e a prática teológico-política do poder político encarnado na pessoa do dirigente e passagem à ideia da dominação impessoal ou da dominação racional, isto é, nascimento da ideia moderna de Estado.

\footnotetext{
7 O projeto moderno não acabou. Certos conhecimentos são usados para continuação do domínio do capital, utilizando-se de saberes locais.Podemos citar como exemplo: megamultinacionais farmacêuticas rotulando remédios naturais e vendendo aos nativos que já sabem do poder desse remédio; a teologia da prosperidade que utiliza a Bíblia como fundamento de sua propaganda; o aprender a língua do colonizado.
} 
Para Giddens (1991), a modernidade "refere-se a estilo, costume de vida ou organização social que emergiram na Europa a partir do século XVII e que ulteriormente se tornaram mais ou menos mundiais em sua influência".

Balandier (1997) define a modernidade contemporânea como o espaço do "movimento de mais incerteza". Incerteza do quê? Ele responde: Face a sua indeterminação, a sociedade é lugar de criação permanente do novo, através das suas incompletudes causadas pelo desejo capitalista excessivo e dos seus vazios. Os indivíduos circulam numa busca incessante de crescimento econômico, patológico que pautam sua relação uns com os outros. Assim há sempre a impossibilidade de se apreender a sociedade e os seus fenômenos de maneira determinística. Desse modo o ser humano fica privado de valores, inclusive religiosos, sendo estes valores sempre fluidos e movimentários, nunca fixos. Algo importante para a religião, uma vez que seus escritos sagrados pretendem ser universais e imutáveis. O conhecimento religioso é imutável (GONÇALVES, 2007).

Giddens (1991) observa que vivemos uma época marcada pela desorientação, pela sensação de que não compreendemos plenamente os eventos sociais e que perdemos o controle. A modernidade transformou as relações sociais e também a percepção dos indivíduos no que se refere à fé.

A modernidade, pode-se dizer, rompe o referencial protetor da pequena comunidade e da tradição, substituindo-as por organizações muito maiores e impessoais. O indivíduo se sente privado e só num mundo em que lhe falta o apoio psicológico e o sentido de segurança oferecidos em ambientes mais tradicionais (GIDDENS, 2002, p. 38).

A fé, segundo Giddens (1991), passa a ser dada ao perito (não mais a divindade) e portanto não mais a religião, que não responde mais nenhum anseio humano. A ciência responde aos anseios do indivíduo. Mas todos esses fatos históricos geram uma crise, pois o projeto moderno falha em sua promessa de dar ao indivíduo e ao povo a prometida liberdade, igualdade e fraternidade. Não se tem liberdade a não ser para consumir o que a comunicação de massa lhe impõe; não há igualdade e sim concentração de renda, e fraternidade é um valor perdido junto com as tradições religiosas. Nem se fala nela mais. Individualismo é o que pauta as relações. 
Porém toda essa crise chamada modernidade não passou despercebida aos religiosos, em suas crenças ferrenhas, em cuja fé repousa sua própria identidade. Assim tal crise provocou reações da religião contra a perda dos valores religiosos que se impunham. Estamos em época de efervescência religiosa (CAMPOS, 2002) e a religião reagiu contra essas mudanças trazidas pela modernidade.

\section{A reação fundamentalista}

Uma dessas reações é o fundamentalismo que surgiu surgiu bem no auge da crise da modernidade, ou seja, no século XX (ADORNO e HORKHEIMER, 2002). A mais dedicada e famosa autora sobre o assunto descreve:

Em todos os tempos e em todas as tradições, sempre houve gente que combateu a modernidade de sua época. Entretanto o fundamentalismo que vamos analisar é um movimento do século XX por excelência. É uma reação contra a cultura científica e secular que nasceu no Ocidente e depois se arraigou $\mathrm{cm}$ outras partes do mundo. O Ocidente criou um tipo distinto de civilizado, totalmente inédito, que desencadeou uma reação religiosa sem precedentes. Os movimentos fundamentalistas contemporâneos têm uma relação simbiôntica com a modernidade. Podem rejeitar o racionalismo científico do Ocidente, mas não têm como fugir dele. A civilização ocidental mudou o mundo. Nada - nem a religião - serão como antes. Em todo o planeta, há pessoas lutando contra essas novas condições e vendo-se obrigadas a reafirmar suas tradições religiosas, que foram concebidas para um tipo de sociedade inteiramente diverso (ARMSTRONG, 2001).

O termo fundamentalismo remete a fundamentos, bases teóricas de uma expressão cultural, está correlato à crença na interpretação literal dos livros sagrados (DREHER, 2002). Seus membros promovem a compreensão literal, ou do que entendem ser literal, de sua literatura sagrada. Não aceitam opinião diversa. Fundamentalistas são encontrados entre religiosos diversos e pregam que os dogmas de seus livros sagrados sejam seguidos à risca ou ao menos se autodefinem assim: como seguidores radicais do texto sagrado.

Não deveria ser tão ruim, recuperar valores religiosos tais como amor e respeito ao próximo, solidariedade, honra (valores defendidos pela 
religiões monoteístas), mas assim como aconteceu com a modernidade. Isso implica certo desastre. Isso porque, apesar de acreditar que se está aplicando uma produção literal, está sempre sendo aplicada uma interpretação, e quase sempre de um interesse pessoal ou escuso de uma pessoa ou de um grupo sobre outros. A palavra fundamentalista a que se faz referência hoje, segundo Elshahed (1992), e que piorou após 11 de setembro de 2001 face à mídia (MOREIRA, 2006), é um termo pejorativo, porém não era essa a ideia inicial dos fundamentalistas.

A obra de Dreher afirma e a de Armstrong sugere que há uma relação profunda entre fundamentalismo religioso e fundamentalismo político. Para os fundamentalistas religiosos, a ação política deve ser sempre orientada pela verdade religiosa. A sociedade perfeita é aquela que se submete à sua compreensão de verdade religiosa. A partir desse princípio, justificam-se intervenções violentas nos Estados independentes e "guerras santas" contra "hereges", matar em nome de Deus, e outras intervenções violentas.

O termo fundamentalismo surgiu nos Estados Unidos (MOLTMAN, 1992), junto à ideia do socialismo, aliado à perda dos valores trazidas pela modernidade, com ideias proporcionadas pelos novos meios de comunicação, em especial pelo rádio. ${ }^{8}$ Essas ideias trouxeram uma forte reação ao humanismo que imperava no pensamento intelectual mundial. Institutos Bíblicos como o fundado em Chicago em 1886 por Dwight L. Moody, o primeiro a se assumir com protestante fundamentalista (STEWARD, 2003), florescia restabelecendo ensinos ortodoxos que haviam sido obscurecidos por escolas humanistas como Harvard, Yale e Princeton. Apregoavam uma volta de Cristo e valores que ofereciam ao indivíduo em crise, causada pela modernidade, uma resposta para a vida. Além disso, apenas alguns anos depois, com a crise de 1929, o fundamentalismo religioso pôde crescer exponencialmente, uma vez que crise econômica proporciona crescimento da religiosidade sem reflexão (PIERUCCI, 1998).

Na medida em que os Estados Unidos entravam no novo século, um crescente número de pessoas corria para se converter nas conferências fundamentalistas, onde aprendiam o que a Bíblia diz sobre o final dos tempos e sobre a segunda vinda de Cristo. Aí está a origem do fundamentalismo (ao menos o cristão, e do termo) (AMMERMAN, 2005).

8 Os fundamentalistas geralmente renegam os produtos e ideais da modernidade, mas usam largamente seus produtos quando lhe interessam (VOLF, 1992). 
Assim a ética moderna de racionalização e crescimento patológico, econômico, que subverteu valores do próprio corpo (BALANDIER, 1997) e de dominação eurocêntrica (idem), os valores das tradições (ALMERI e MELO, 2009) e da fé (GIDDENS, 1991). O fundamentalista, sobretudo o americano, não aceitou tal visão, mas pretendeu e pretende mudar as orientações do mundo, visto que surgiu com uma nobre intenção de recuperar supostos bons valores como a família, a honra e moral e os bons costumes (AMMERMAN, 2005).

Porém perverte esses bons costumes utilizando-se de violência e terror quando confrontados com ideias opostas (ARMSTRONG, 2001). O fundamentalista religioso não baseia seu discurso, e expressa sua fé na experiência pessoal com sua divindade, mas nos dogmas, entendidos como realidades fixas, imutáveis e livre de qualquer possível interpretação (apesar de que todo fundamentalismo é uma interpretação) ou exegética. Ora, os textos e os dogmas religiosos não nasceram por si mesmos, mas foram definidos pelos credos religiosos, a partir de uma interpretação supostamente permitida pela divindade (SIMMEL, 2009).

Aliás, uma boa definição de fundamentalismo seria aquele que usa de proselitismo militante (VOLF, 1992). Sem militância não há fundamentalismo, nem toda atitude radical ou violenta seria fundamentalismo. Só há fundamentalismo quando há uma posição militante.

O fundamentalismo religioso não vê o dogma no contexto histórico da sua constituição e definição (EISENSTAD, 1997), vê apenas o que entende ser correto. Faz uma interpretação ora literal, ora interesseira do seu escrito, recusando-se radicalmente a admitir interpretações diferentes (idem). O fundamentalismo assim o faz visto sentir sua fé ameaçada e fragilizada pela modernidade.

Embora seja uma reação à modernidade, utilizam seus produtos e benesses, em especial os meios de comunicação para fazer seus prosélitos, para modernizar suas pensões de fundos, para promover-se e defender-se no meio político (COLEMAN, 1992). Enquanto qualquer fundamentalismo, como ideia de que a única verdade está no texto sagrado, pode se considerar portador de um caminho humanitário de redenção, sua apropriação por facções que pretendem impor sua fé pela conquista e pela eliminação ou sujeição das outras, levou a um confronto em que se misturam religião, política, violência e terrorismo, em meio a muitas distorções e marketing (AMMERMAN, 1987). 


\section{Vivendo na modernidade e reagindo contra ela}

Coleman (1992) diz que os fundamentalistas "procuram viver na modernidade (e influenciar sua orientação), mas sem dela fazer parte" (p. 23). O objetivo do fundamentalista é moldar o mundo segundo sua visão. Não querem algo ateu e capitalista mudando o mundo (embora existam fundamentalistas ateus capitalistas); querem sua visão de sagrado dirigindo o mundo.

Existem vários tipos de fundamentalismo, e que reagem à modernidade de modo diferente, mas com a mesma ideia de moldar o mundo. No judaísmo promovem a segregação ortodoxa de forma social e luta política internacional em conflito com palestinos (NEUSNER, 1992). No islã matam e obrigam mulheres em submissão não condizentes aos valores de igualdade (GASPARD, 2007). Nos EUA, protestantes matam profissionais de saúde que acompanham processos abortivos ao mesmo tempo em que se influenciam na política estadual e nacional de modo a influenciar até a educação (AMMERMAN, 2005). ${ }^{9}$

Em reportagem que teve impacto na opinião publica, a jornalista Küchler (2005) expõe de forma resumida e brilhante algumas organizações fundamentalistas atuantes no mundo:

\section{Grupos judaicos}

\section{- Kach Kahane Chai}

Objetivo: Restabelecer os territórios judaicos como determina a Torá e expulsar os palestinos da região.

Modo de agir: Atentados terroristas em Israel. Em 1994, Baruch Goldstein, seguidor do Kach, matou 29 palestinos que rezavam na Caverna dos Patriarcas, em Hebron.

\section{- Neturei Karta}

Objetivo: Oposição ao sionismo. O grupo acredita que Israel é obra de Satã e que judeus não devem se envolver em política ou luta armada, só em assuntos espirituais.

Modo de agir: Boicote. Em 1948, quando o Estado de Israel foi criado, o grupo proibiu todos os seus membros de participarem de eleições, recusou subsídios governamentais para suas escolas e jurou que não entraria em nenhuma instituição governamental. No ano passado, quando o líder da Autoridade Palestina, Iasser Arafat, morreu, membros do Naturei Karta visitaram o túmulo dele. Muitos membros do grupo apoiam a criação de um Estado palestino.

\footnotetext{
9 Há pouco tempo, em especial após os acontecimentos de 2001, foi proibido em vários estados americanos, por exemplo o ensino evolucionista e substituído pelo criacionista.
} 


\section{- Satmar}

Objetivo: Oposição ao sionismo. É um dos maiores grupos ultraortodoxos existentes hoje. Surgido na Romênia, vê o Estado de Israel como profanação. Acredita que o povo eleito deve sofrer a punição do exílio e não tomar iniciativas para se salvar, confiando na vontade de Deus.

Modo de agir: Encoraja os seguidores a criarem comunidades fora de Israel. O líder do grupo, rabino Joel Teitelbaum, culpa os sionistas pelo Holocausto, pois "atraíram a maioria dos judeus para uma hedionda heresia, como nunca se viu desde a criação do mundo".

\section{Grupos islâmicos}

- Partido Frente Islâmica de Salvação

Objetivo: Fundar uma república islâmica regida pelas leis do Alcorão, na Argélia.

Modo de agir: Política. Em 1991, o partido iria ganhar as eleições, mas o governo interrompeu o processo eleitoral. A medida gerou revolta entre os muçulmanos e uma guerra civil durante toda a década de 1990. Deste conflito, surgiram os grupos fundamentalistas Exército Islâmico da Salvação e Grupo Armado Islâmico.

- Al-Gama a al-Islamiyya

Objetivo: Pela guerra santa, fazer do Egito um Estado islâmico.

Modo de agir: Ataques terroristas, em especial contra turistas. "O turismo é uma praga. As mulheres vêm vestidas em roupas provocativas para despertar o desejo dos fiéis", disse o líder Omar Abdel Rahman a um jornal israelense em 1993. Em 1997, o grupo matou 58 pessoas que visitavam o templo de Hatshepsut, um dos principais pontos turísticos do país. Também já cometeu um ataque contra o presidente egípcio Hosni Mubarak, em 1995.

- Abu Sayyaf

Objetivo: O grupo, ligado à $\mathrm{Al}$ Qaeda, quer criar um Estado islâmico nas Filipinas.

Modo de agir: Ataques terroristas. É acusado de ter matado 100 pessoas no ataque a um barco, em fevereiro de 2004. No dia 14 de fevereiro deste ano, dia dos namorados nas Filipinas, 3 atentados à bomba mataram 11 pessoas. Os ataques seriam um presentinho para a presidente Gloria Arroyo.

\section{Grupos cristãos}

- Pró-vida de Anápolis

Objetivo: Combater o aborto em qualquer caso, o homossexualismo e o uso de preservativos. 
Modo de agir: Campanhas e lobbies junto a vereadores e deputados. $\mathrm{O}$ grupo luta contra ações judiciais que permitem certos tipos de aborto e é reconhecido como entidade de utilidade pública por uma lei municipal de Anápolis.

- Christian Voice (Voz Cristã)

Objetivo: Analisar os acontecimentos atuais sobre a ótica da Bíblia, unir Igreja e Estado na Inglaterra. "Abençoada é a nação em que Deus é o senhor", informa o site do grupo.

Modo de agir: Manifestações de oposição à União Europeia e ao divórcio, ataques a clínicas de aborto e promoção da cura de homossexuais. No começo do ano, o grupo fez uma manifestação contra a tevê britânica BBC por ter apresentado o musical Jerry Springer - The Ópera em que Jesus, Maria e Deus são convidados de um programa de entrevistas no inferno e Jesus diz que é gay. Telefones de funcionários da $\mathrm{BBC}$ foram divulgados no site do grupo para quem quisesse reclamar pessoalmente.

- Universidade Bob Jones

Objetivo: Formar profissionais preparados para seguir Cristo, independentemente da carreira.

Modo de agir: Os estudantes são obrigados a participar de um curso bíblico por semestre. Proíbe namoros entre estudantes de raças diferentes e expulsa alunos homossexuais.

Engana-se quem pensa que os fundamentalistas são pessoas alienadas, talvez sua massa de manobra seja, porém suas lideranças são pessoas extremamente esclarecidas e cônscias do que ocorre na modernidade. Um dos grupos fundamentalistas mais agressivos e politizados do fundamentalismo mulçumano é o Talebã, cuja tradução significa estudantes, ou seja, são estudantes universitários conscientes da crise da modernidade, que perverte ou acaba com seus valores caros e são reagentes com isso. O mesmo vale para o fundamentalismo cristão atual político norte-americano: ${ }^{10}$ são extremamente bem estudados, ricos, industriais com todos os acessos às benesses da educação (AMMERMAN, 2005). O mesmo vale para o fundamentalismo judeu: são pessoas partidárias na política e eruditas, envolvidas com o conflito político (LEIBOWITZ, 1993).

${ }^{10}$ É talvez o mais atuante dos fundamentalismos, especialmente após 2001. Influenciaram-se na política norte-americana de uma maneira muito contundente. 


\section{Conclusão}

Vale lembrar que os fundamentalistas não são exclusivamente religiosos. Há o fundamentalismo ateu, político e até antirreligioso, porém (OSA, 2008) o religioso é o que está mais em voga depois dos acontecimentos de setembro de 2001. Este assunto se torna interessante quando consideramos que o ano 2000 representava uma esperança do advento do capital, uma superação da promessa que ficaria tudo perfeito, o mercado entraria em equilíbrio, visto que havia ausência de conflitos e crescimento do PIB mundial (BRAGA e CINTRA, 2004). Entre 1980 e 2006, o primeiro cresceu mais de 14 vezes, enquanto o segundo não chegou a cinco (idem).

Resumamos. Os anos que cruzam 1990 e 2000 foram de explosão das "finanças diretas" (ativos, títulos, ações etc.), de multiplicação para trilhões os valores nocionais dos derivativos (especulação financeira sobre ativos futuros) e de crises financeiras cada vez mais demolidoras (TAVARES e BELLUZO, 2009). Essa crise iniciou em 2007 com a chamada "bolha" imobiliária e suas falhas e estouros, nos EUA, e foi agravada severamente com a falência de empresas como a ENRON e sua relação com a quebra do banco Lehman Brothers em setembro de 2008 (idem).

Assim o modo de como o mundo encara o fundamentalismo mudou após os acontecimentos de setembro de 2001. Serviu a novos interesses políticos, uma manutenção do poder de um fundamentalismo protestante no governo dos EUA, a uma manifestação legitima de não aceitar o preço (e lutar por isso) que os EUA queriam pagar pelo petróleo por parte dos fundamentalistas árabes, de justificar um incremento no conflito da Palestina com apoio norte-americano. Aliado a tudo isso ocorre recentemente no Brasil (COSTA DE SOUZA, 2009), assim como na América Latina (MELANDER, 2000), um fundamentalismo religioso católico (FOUILLOUX, 2001) e protestante extremamente envolvido na política, surgida com o declínio dos regimes totalitários na América Latina. ${ }^{11}$ Esses devem ser vistos e estudados de perto uma vez que sua militância, se bem sucedida, envolve riscos para as conquistas de direitos humanos.

Os meios de comunicação proporcionaram para os fundamentalistas extremos e ilimitados meios para eles divulgarem suas ideias,

${ }^{11}$ Durante o século XX, diversos regimes totalitários surgiram por toda Americalatina. 
conquistarem adeptos e imporem suas vontades. De certo modo oferecem respostas senão corretas, ao menos estáveis em um mundo caótico, configurado pela modernidade e sua crise. As pessoas podem, em certo momento, procurar tais repostas estáveis e concretas para um direcionamento em suas vidas. Essa talvez seja a arma mais perigosa para o avanço fundamentalista: o próprio mundo instável no qual ele é ao mesmo tempo produto (ainda que errado), é também uma resposta para a instabilidade da modernidade, pois oferece ao indivíduo uma resposta, um caminho estável e que pode explicar (se o indivíduo caminha pela modernidade estaria fora dos caminhos divinos) as agruras do cotidiano.

A resposta para esse problema talvez esteja na proposta de um novo fundamentalismo, digamos, um fundamentalismo esclarecido (se é que isso é possível), um que proponha como fundamentos de sua religiosidade as ideias que não produzam vítimas (CERTEAU, 1998), onde o fundamento das configurações cristãs seja o amor ao próximo; das judaicas, o relacionamento com Yavhé e da sua benignidade; das mulçumanas, do caminho da submissão e da bondade. Ou seja, que seus fundamentos sejam os condizentes com as conquistas de direitos humanos conseguidas a muito custo pelo Estado democrático, e da promoção de um Estado laico que garanta o respeito às culturas e à liberdade religiosa.

Outro caminho é que a ciência e a racionalidade aceitem suas falhas. Deve-se ter uma devolução dos "saberes sequestrados", uma proposição e uma luta pelo direito inalienável dos povos ao patrimônio cultural da humanidade, pela democratização dos saberes, das culturas, da comunicação e das tecnologias, valorizando os bens comuns com a finalidade de dar visibilidade aos saberes subjugados, e pelo fim do conhecimento privado e hegemônico, e por mudanças fundamentais do sistema de mídia. Seria um avanço utópico porém funcional para o fim do fundamentalismo a criação de uma sociedade que não tivesse tanto a necessidade de crescimento racional, patológico e de conhecimento jungido ao poder capital. Tal sociedade só pode existir com investimento massivo em uma educação cultural, critica, ética e ecológica.

\section{Referências}

ADORNO, T.; HORKHEIMER, M. The dialectic of Englightenment. Stanford University Press, 2002. 
ADORNO, Theodor W. A indústria cultural. In: COHN, Gabriel. Comunicação e indústria cultural. São Paulo: Nacional, 1971.

ALMERI, Karina Bradandi; MELO, Edgar. Índia: os caminhos da fé e da modernidade. São Paulo: Escala, 2009.

AMMERMAN, Nancy T. Bible Believers. Fundamentalists in the Modern World. New Brunswick: RutgersUniversity Press, 1987.

AMMERMAN, Nancy T. Pillars of Faith: American Congregations and their Partners, Berkeley: University of California Press, 2005.

ARMSTRONG, K. Em nome de Deus: o fundamentalismo no judaísmo, no cristianismo e no islamismo. São Paulo: C. Letras, 2001.

BALANDIER, G. O contorno: poder e modernidade. In: O Imaginário na Modernidade. Rio de Janeiro: Bertrand, 1997.

BAUDRILLARD, Jean. La Crítica de Economia Política Del Signo. In: MOREIRA, Roberto C. S. Teoria da Comunicação: ideologia e utopia. Petrópolis: Vozes, 1979.

BERNANOS, G. O espírito europeu e o mundo das máquinas. In: Texto integral das conferências e dos debates dos Encontros Internacionais de Genebra. Lisboa, PT: Ed. Europa-América, 1962. (Colecção Encontros Internacionais de Genebra).

BOLAÑO, César Ricardo Siqueira. Sociedade da informação: reestruturação capitalista e esfera pública global. Estudos de Sociologia, n. 8, Araraquara: UNESP, 1998.

BOURDIEU, Pierre. Gênese e estrutura do campo religioso. In: MICELI, Sergio (Org.). A economia das trocas simbólicas. São Paulo: Perspectiva, 1974.

BRAGA, J. C. S.; CINTRA, M. A. M. Finanças dolarizadas e capital financeiro: exasperação sob comando americano. In: FIORI, J. L. (Org.). O poder americano. Petrópolis, RJ: Vozes, 2004.

BUBER, M. (1937). Eu e vós. São Paulo: Centauro, 2001.

CAMPOS, Leonildo Silveira. As mutações do campo religioso. In: Caminhando, v. 7, n. 1 [9], p. 97-109, 2002. [Online, 2009]. Disponível em: <http://www.sumarios.org/ sites/default/files/pdfs/343684381.pdf>. Acesso em: 06 dez. 2012.

CAPRA, Fritjof. O ponto de mutação: a ciência, a sociedade e a cultura emergente. 25. ed. São Paulo: Cultrix, 1982. 447 p.

CERTEAU, M. Artes de fazer, a invenção do cotidiano. 3. ed. Vozes, 1998.

COLEMAN J. A. Fundamentalismo global, perspectivas sociológicas. In: Concilium, n. 241, p. 53-64, 1992/3.

COSTA DE SOUZA, Robson da. Identidades fundamentalistas em face dos "processos emancipatórios modernos". ANAIS DO II ENCONTRO NACIONAL DO GT HISTÓRIA DAS RELIGIÕES E DAS RELIGIOSIDADES. In: Revista Brasileira de História das Religiões - ANPUH, Maringá (PR), v. 1, n. 3, 2009. ISSN 1983-2859. Disponível em: <http://www.dhi.uem.br/gtreligiao/pub.html>. Acesso em: 02 abr. 2013. 
DONNELLY, M. Sobre los diversos usos de la noción de biopoder. In: Michel Foucault, Filósofo. Barcelona: Gedisa, 1999. p. 193-197.

DREHER, M. N. Para entender o fundamentalismo. São Leopoldo: Unisinos, 2002.

EISENSTAD S. N. Fundamentalismo e modernidade. São Paulo: Celta, 1997.

FÉLIX, Luciene. Darwin, Nietzsche e Freud - Deus está morto? Revista Brasileira de Direito Constitucional, v. 17, n. 1, 2008. Disponível em: <http:/www.esdc.com.br/ CSF/artigo_2008_08_darwin.htm>. Acesso em: 26 mar. 2012.

FERRETI G. Max Scheler, fenomenologia e antropologia personalistica. Trad. EDUSP. Milão: Vita e Pensiero, 1972.

FOUCAULT, Michel. Arqueologia das ciências e história dos sistemas de pensamento. Organização e seleção de textos Manoel Barros da Motta. Tradução de Elisa Monteiro. 2. ed. Rio de Janeiro: Forense Universitária, 2008. (Ditos e Escritos, II).

FOUILLOUX, Étienne. Integrismo católico e direitos humanos. In: ACAT, Fundamentalismos integrismos. São Paulo: Paulinas, 2001. Cap. 1.

FRESTON, Paul. Breve história do pentecostalismo brasileiro. In: ANTONIAZZI, Alberto et al. Nem anjos, nem demônios: interpretações sociológicas do pentecostalismo. Petrópolis: Vozes, 1994.

GASPARD, Françoise. O véu da disputa. In: Mandrágora, São Bernardo do Campo: Universidade Metodista de São Paulo, ano 13, n. 13, p. 107-116, 2007.

GIDDENS, Anthony. As consequências da modernidade. São Paulo: Unesp, 1991.

GIDDENS, Anthony. Modernidade e identidade. Rio de Janeiro: Jorge Zahar Editor, 2002.

GONÇALVES, E. P. Iniciação à pesquisa científica. Campinas: Alínea, 2007.

HEIDEGGER, Martin. Nietzsche. Tradução de Marco Antônio Casanova. Rio de Janeiro: Forense Universitária, 2007. v. II.

HORKHEIMER, M. Sobre el concepto de la razón. Traduçao de J. Godo Costa. Barcelona: Ediciones Península, 1976.

HUYSSEN, A. After the great divide, Modernism, mass culture and postmodernism. Bloomington: Indiana University Press, 1986.

KANT, I. Crítica Da Razão Pura. In: Kant - vida e obra. São Paulo: Nova Cultural, 1996.

KÜCHLER, A. O que é fundamentalismo? Revista Superinteressante, São Paulo: Ed. Abril, n. 215, jul. 2005. [Online]. Disponível em: <http://super.abril.com.br/religiao/ fundamentalismo-445747.shtml>. Acesso em: 30 mar. 2013.

KUHN, Thomas. A estrutura das revoluções cientificas. 5. ed. São Paulo: Perspectiva, 1998.

LEIBOWITZ, Yeshayahou. Judaïsme, Peuple Juif et Etat D'Israel. Paris: Jean Claude Lattes, 1993. Cap. 10, p. 169-183. 
LYOTARD, Jean-François. The Postmodem Condition: A Report on Knowledge. Minneapolis: University of Minnesota Press, 1984.

MARTELLI, Stefano. A Religião na sociedade pós-moderna, entre secularização $e$ desseculirazação. São Paulo: Paulinas, 1995.

MARTY, M. E. O que é fundamentalismo? Perspectivas teológicas. In: Concilium, n. 241, p. 13-26, 1992/3.

MARX, Karl. Das Kapita. Tradução para o francês de Regis Cardench. Paris: Le nouvelle livre, 1996. Livre I, 2 v.

MELANDER, Veronica. Os limites da categoria "fundamentalismo" para o estudo de religião e política na Guatemala. Ciencias Sociales y Religión/Ciências Sociais e Religião, Porto Alegre, ano 2, n. 2, p. 87-118, set. 2000.

MOLTMAN, Jürgen. Fundamentalismo e modernidade. In: Concilium, n. 241, p. 141-148, 1992.

MONDIN, B. O homem, quem é ele? Elementos de antropologia filosófica. São Paulo: Paulus, 1980.

MONOD, Jacques. Chance and Necessity. An Essay on the Natural Philosophy of Modern Biology. New York: Alfred A. Knopf, 1971.

MOREIRA, Deodoro José. Mídia, fundamentalismo e terror: A lógica da barbárie, UNIrevista, São Leopoldo, v. 1, n. 3, jul. 2006.

MORIN, E.; PRIGOGINE, Ilya. A sociedade em busca de valores. Para fugir à alternativa entre cepticismo e o dogmatismo. Tradução (do francês) de Luis M. Conceiro Feio. Lisboa: Instituto Piaget, 1996.

MORIN, E. Saberes globais e saberes locais - o olhar interdisciplinar. Rio de Janeiro: Garamond, 2000.

MORIN, E. Ciência com consciência. Tradução (do francês) de Maria D. Alexandre e Maria Alice S. Doria. Ed. rev. e mod. pelo autor. Rio de Janeiro: Bertrand Brasil, 1996.

MORIN, E. O Problema epistemológico de complexidade. Lisboa: Europa-América, 1983.

MORIN, E. Os sete saberes necessários à educação do futuro. Tradução (do francês) de Catarina Eleonora F. da Silva e Jeanne Azuaya. São Paulo: Cortez; Brasília: Unesco, 1999.

MUNFORD, L. The transformation of Man. Nova York: Harper, 1956. p. 172-173.

NEUSNER, J. O desafio do fundamentalismo Judaico contemporâneo. In: Concilium, n. 241 , p. $67-71,1992 / 3$.

OSA, José Alberto Escobar Marín. El fenómeno del fundamentalismo de corte religioso y diferencias relevantes para el ordenamiento jurídico. Anuario Jurídico y Económico Escurialense, época II, n. XLI, 2008. ISSN: 1133-3677. 
OZAÏ SILVA, A. Anotações sobre a modernidade na obra de Anthony Giddens. Revista Espaço Acadêmico - UEM, v. VI, n. 47, abr. 2005, Disponível em: <http://www. espacoacademico.com.br/047/47pol.htm>. Acesso em: 21 set. 2013.

PANIKKAR, Raimon. Morte e ressurreição da Teologia. Horizonte, Belo Horizonte, v. 4, n. 7, p. 15-29, dez. 2005.

PEDRERO-SÁNCHES, Maria Guadalupe. História da Idade Média: textos e testemunhas. São Paulo: UNESP, 2000.

PIERUCCI, Flávio. Secularização em Max Weber. Da contemporânea serventia de voltarmos a acessar aquele velho sentido. Revista Brasileira de Ciências Sociais, n. 37 , p. 43-73, 1998.

REIS, José Carlos. (2003). História e teoria. historicismo, modernidade, temporalidade e verdade. 3. ed. Rio de Janeiro: ed. FGV, 2006.

RORTY, R. Consequences of pragmatism. Minneapolis: University of Minnesota Press, 1982

RORTY, Richard. Contingency, irony and solidarity. Cambridge: Cambridge University Press, 1989.

SCHELER, M. A posição do homem no cosmos. Trad. Marco Antônio Casa Nova. Rio de Janeiro: Forense Universitária, 2003.

SIMMEL, G. Religião: ensaios. São Paulo: Olho d’Água, 2009. 144 p.

STEWARD, Milton e Lyman (1910). Fundamentals: A testimony to the truth. Michigan: R. A. Torrey; Baker Books, 2003. 1480 p.

TAVARES, M.; BELLUZO, L. A. Mundialização do capital e a expansão do poder americano. In: FIORI, J. L. (Org.). O poder americano. Petrópolis: Vozes, 2004.

TOURAINE, Alain. Uma visão critica da modernidade. In: A modernidade. Cadernos de Sociologia, UFRGS, v. 5, n. 5, 1993.

TOURAINE, Alain. Crítica da modernidade. Petrópolis: Vozes, 2002.

VOLF, Miroslav. O desafio do fundamentalismo protestante. In: Concilium, n. 241, p. $125-137,1992$.

WESTHELE, Vítor. Teologia e Pós-modernidade. In: MARASCHIN, Jaci (Org.). Teologia sob limite. São Paulo, ASTE, 1992. p. 143-166.

WESTHELLE, Vitor. Traumas e opções: Teologia e a crise da modernidade. Centro de Estudos Anglicanos, 2008. Disponível em: <http://www.centroestudosanglicanos. com.br/bancodetextos/diversos/teologia_crise_modernidade_vitor.pdf $>$. Acesso em: 30 mar. 2013.

\section{Leituras sugeridas:}

DREHER, M. N. Para entender o fundamentalismo. São Leopoldo: Unisinos, 2002.

GIDDENS, Anthony. As consequências da modernidade. São Paulo: Unesp, 1991. 
LYOTARD, Jean-François. The postmodem condition: A report on knowledge. Minneapolis: University of Minnesota Press, 1984.

MARTELLI, Stefano. A Religião na sociedade pós-moderna, entre secularização e desseculirazação. São Paulo: Paulinas, 1995.

TOURAINE, Alain. Crítica da modernidade. Petrópolis: Vozes, 2002.

Recebida: $17 / 06 / 2014$

Avaliada: 28/06/2014 